\title{
ALGUNOS ASPECTOS DE LOS EUFEMISMOS Y DISFEMISMOS CONSIDERADOS COMO CLASES DE METÁFORAS
}

\author{
SOME ASPECTS OF EUPHEMISMS \\ AND DYEPHEMISMS CONSIDERED AS \\ KINDS OF METAPHORS
}


En las últimas décadas, la metáfora ha tomado gran fuerza en los estudios lingüísticos. Ha sido concebida como un mecanismo del pensar, que, por otra parte, se refleja también en el obrar (v. gr. Lakoff y Johnson, 1980; Lakoff, 1987). El presente trabajo hará referencia primeramente a esta renovada mirada de la metáfora surgida en los años ochenta. Luego, se realizará una fundamentación de la consideración de los eufemismos y disfemismos como clases especiales de metáforas. A continuación, se ejemplificará lo desarrollado con base en un corpus textual reunido por Elena Fernández de Molina Ortés (2014) y Eliecer Crespo Fernández (2008). Finalmente, se presentará una conclusión.

Palabras ClaVe: metáfora conceptual, eufemismo, disfemismo, ejemplos

In recent decades, metaphor has become very strong in linguistic studies. It has been conceived as a mechanism of thought, which, moreover, is also reflected in behaviour (v. gr., Lakoff and Johnson 1980; Lakoff 1987). This paper will refer firstly to this renewed vision of metaphor emerged in the eighties. Then, a justification for considering dysphemisms and euphemisms as special metaphors classes will be made. Subsequently, developed concepts will be exemplified with a corpus collected by Elena Fernandez de Molina Ortés (2014) and Eliecer Crespo Fernández (2008). Finally, a conclusion will be presented.

KEY WORDS: conceptual metaphor, euphemism, dysphemism, examples

RECEPCIÓN: 29/06/2015

ACEPTACIÓN: 8/11/2015 


\section{ALGUNOS ASPECTOS DE LOS \\ EUFEMISMOS Y DISFEMISMOS \\ CONSIDERADOS COMO CLASES \\ DE METÁFORAS}

\section{SOME ASPECTS OF EUPHEMISMS AND DYEPHEMISMS CONSIDERED AS KINDS OF METAPHORS}

Daniela Soledad Gonzalez

UNCuyo-Conicet

\section{Metaphors we live by y la explosión de los estudios sobre la metáfora conceptual}

La metáfora ha sido estudiada desde antiguo. Si bien Aristóteles desarrolla el aspecto figurativo de la retórica, que retomarán los estudiosos de la retórica clásica, ${ }^{1}$ habilita también la lectura de la metáfora como un fenómeno del pensamiento, que fue propagada particularmente a partir de los estudios de

\footnotetext{
${ }^{1}$ Sobre los estudios que la retórica clásica llevó a cabo sobre el tema, baste decir que esta disciplina desarrolló un aspecto importante de los conceptos aristotélicos sobre la metáfora, concibiéndola como un recurso o figura retórica. Definió y estableció relaciones entre símil, metáfora, metonimia y sinécdoque. Concibió la metáfora como la identificación verbal de algo presente con algo evocado, algo así como una comparación incompleta en la cual no estaba presente como. Para mayores detalles, véase el Manual de Retórica y recursos estilísticos, de Ángel Romera, disponible en la web.
} 
Lakoff y Johnson en $1980 .^{2}$ Sin embargo, fue en las últimas décadas cuando se dio una explosión de estudios sobre este asunto (Martín de la Rosa, 2002), entre los cuales resultan particularmente importantes aquellos que indagan las relaciones entre lenguaje y pensamiento (Lakoff y Johnson, 2001 [1980]; Lakoff, 1987).

Lakoff y Johnson constatan que la comprensión de la metáfora generalmente no es diferente de la comprensión del lenguaje literal. Indican que nuestro sistema conceptual se estructura a través de conceptos metafóricos: la metáfora halla semejanzas entre dos dominios, uno abstracto y otro concreto, con el fin de facilitar la comprensión del dominio abstracto (generalmente). Así, en la metáfora EL AMOR ES UN VIAJE, por ejemplo, el dominio abstracto de AMOR se conceptualiza en términos de otro, el de VIAJE, que está mejor delineado en la mente humana debido a la experiencia que implica en las interacciones corporales del individuo con su entorno.

Esta consideración de la primacía de la experiencia es lo que se ha denominado experiencialismo, en inglés embodiment. La experiencia - fundamentalmente la corporal, pero también la cultural- es el fundamento de los conceptos metafóricos. Ello sería una explicación de por qué en la mayoría de los casos las metáforas dan expresión a realidades abstractas en términos de otras más concretas. ${ }^{3}$

\footnotetext{
${ }^{2}$ Para una fundamentación de esta última afirmación, Kirby (1997) y Vaquera Márquez (1984).

${ }^{3}$ En relación con esto puede traerse a colación la siguiente observación de los autores: las teorías científicas suelen ser, en muchos casos, metafóricas, y "La capacidad de atracción intuitiva de una teoría científica tiene que ver con el
} 
Lakoff y Johnson (2001: 3) señalan también que "nuestro sistema conceptual ordinario, en términos tanto de lo que pensamos como de lo que actuamos, es fundamentalmente de naturaleza metafórica". Sostienen que "la esencia de la metáfora es entender y experimentar un tipo de cosa en términos de otra" (Lakoff y Johnson, 2001: 40). Además, arguyen que las acciones, eventos y objetos se entienden en términos de gestalts experienciales, i. e., todos estructurados y significativos dentro de la experiencia, que le dan a esta una coherencia y la estructuran. Por ejemplo, la metáfora LA DISCUSIÓN ES UNA GUERRA estructura no solo la forma en la que hablamos acerca de las discusiones (atacó el punto débil de mi argumento, defendió una posición), sino también el modo mismo de concebir y llevar a cabo discusiones en nuestra cultura. Los autores señalan, además, que el hecho de destacar un aspecto de una cosa en virtud de la metáfora que se establece con ella, lleva a ocultar otros aspectos.

\section{El eufemismo y el disfemismo: clases de metáforas}

Chamizo Domínguez, siguiendo a Allan y Burridge, entiende por eufemismo lo siguiente: "A euphemism is used as an alternative to a dispreferred expression, in order to avoid possible loss of face either one's own face or, through giving offense, that of the audience, or of some third party". Por el contrario, "A dysphemism is an expression with conno-

acierto con que sus metáforas se ajusten a la experiencia personal" (Lakoff y Johnson, 2001: 56). Para mayor información sobre el concepto de embodiment, Ziemke (2003). 
tations that are offensive either about the denotatum or to the audience, or both, and it is substituted for a neutral or euphemistic expression for just that reason" (2004: 45).

El autor español afirma que todas las características que definen a las metáforas se pueden aplicar también a los eufemismos y a los disfemismos. Estas características son las siguientes: "consiste en dar a una cosa el nombre que pertenece a otra", lo cual "conlleva característicamente una falsedad categorial", y puede ser definida como una transferencia desde un dominio conceptual (el dominio fuente) a otro (el dominio meta), como ya se explicó en el apartado anterior.

Teniendo en consideración esto, Chamizo Domínguez sostiene que los eufemismos y los disfemismos podrían ser considerados como metáforas, o al menos como un caso especial de metáfora. Afirma también que poco es lo que se ha estudiado sobre estos recursos considerándolos desde esta perspectiva. ${ }^{5}$ Otros autores que afirman que los recursos eufemísticos son metáforas son Busquet (2007: 79), Crespo Fernández (2005: 81; 2008: 43) y Fernández de Molina Ortés (2014: 11).

Teniendo, claramente, en mente estas nociones, Elena Fernández de Molina Ortés (2014: 9) agrega la siguiente

\footnotetext{
${ }^{4}$ Esta definición remite al significado etimológico del término (meta + phor) pher: 'llevar a través de') y pertenece a Aristóteles: “traslación de un nombre ajeno, o desde la especie al género, o desde el género hasta la especie, o desde una especie a otra especie, o según la analogía” (1974: 1457b 7-9).

${ }^{5}$ Los estudios que cita el autor son Pfaff, Gibbs y Johnson (1997) y Chamizo Domínguez y Sánchez (2000).
} 
nota a la definición del eufemismo (que se extiende a la de disfemismo):

La voz eufemismo proviene etimológicamente del griego y se refiere al "que habla bien, que evita las palabras de mal agüero". Esta definición relaciona directamente este concepto con la necesidad de la existencia de una traslación semántica procedente del vocabulario mágico y religioso; ${ }^{6}$ según esta hipótesis, el eufemismo sería la sustitución de un elemento por otro debido a un factor psicológico: el temor. En cambio, como expone Casas Gómez (1986: 85), el eufemismo ha abandonado en la actualidad su tendencia primaria con una intención afectiva y social. Como fenómeno inverso al eufemismo se encuentra el disfemismo, cuyo uso parece estar motivado por la ruptura con los convencionalismos sociales de los que forman parte las voces eufemísticas.

Como puede observarse en esta definición, se habla de una "traslación", que subyace a los procedimientos eufemísticos y disfemísticos. Esta traslación es mentada también por la idea de "sustitución de un elemento por otro"? Otra expresión de la autora refuerza la idea de que los $\mathrm{x}$-femismos ${ }^{8}$ son metáforas: "podemos definir el eufemismo como una

\footnotetext{
${ }^{6}$ Véase Crespo Fernández (2005: 63).

${ }^{7}$ No es momento de discutir las teorías de la sustitución en los estudios sobre la metáfora. Se prefiere comprender la idea de fondo de la autora con buena voluntad. Lo que llama sustitución puede ser comprendido como interacción o proyección de dominios. Quien esté interesado en una extensa disquisición sobre las diversas aproximaciones teóricas al tema de la metáfora, véase Gibbs (1992) y Ricoeur (1980 [1975]).

${ }^{8}$ Cuando se utiliza el término $x$-femismos se engloba tanto a los eufemismos como a los disfemismos.
} 
actualización discursiva en la que el hablante emplea ciertos recursos lingüísticos y paralingüísticos que le permiten, en un situación pragmática concreta, sustituir el término interdicto" (Fernández de Molina Ortés, 2014: 10). ${ }^{9}$

Habiendo establecido la naturaleza metafórica de los $\mathrm{x}$-femismos, es menester revisar distintos aspectos que refuerzan esta identificación. Un rasgo metafórico interesante del eufemismo — que puede extenderse al disfemismo-, señalado por Chamizo Domínguez, es la ambigüedad. No puede haber eufemismo o disfemismo si no cabe una diversidad de significados como interpretación de la expresión $\mathrm{x}$ femística. Además, señala que "un eufemismo no puede ser reemplazado por ninguna otra palabra y seguir surtiendo los mismos efectos cognitivos, estilísticos, sociales, etc. La razón de ello estriba en la inexistencia de sinónimos estrictos en una lengua natural dada" (2004: 45). ${ }^{10}$

La ambigüedad que poseen los $\mathrm{x}$-femismos se soluciona "en discurso". Un eufemismo o disfemismo lo es de acuerdo con el contexto en el que es enunciado y en relación con las intenciones del hablante, sus creencias, los conocimientos de los participantes en el intercambio lingüístico, los gestos, etc. Es en función de todos esos elementos que una determinada expresión puede ser entendida literal, metafórica, eufemística, disfemística o irónicamente.

\footnotetext{
${ }^{9}$ La negrita es de la autora del presente artículo. No se discutirá el asunto de la sustitución como característica esencial de la metáfora. Sea que se la comprenda como sustitución, sea que se la entienda como interacción entre dominios, lo cierto es que la metáfora consiste en una proyección que se produce entre dos elementos (términos, dominios, espacios).

${ }^{10}$ A este respecto, se puede consultar también el trabajo de Crespo Fernández (2005: 81).
} 
De hecho, cuando el oyente no es cooperativo desaparece el efecto eufemístico. Por ello, las fronteras entre los eufemismos y los disfemismos son muy borrosas en algunas ocasiones. Es más, son convertibles el uno al otro (Chamizo Domínguez, 2004: 45). ${ }^{11}$ Incluso, se pueden producir procesos mixtos, por los que se utiliza una expresión eufemística con una intención disfemística o viceversa. Estos fenómenos mixtos han sido denominados por Crespo Fernández "cuasieufemismos" y "cuasidisfemismos". 12

Otra característica metafórica de los $\mathrm{x}$-femismos es que existen estadios en su vida: el eufemismo novedoso, el semilexicalizado y el lexicalizado (Crespo Fernández, 2005: 83-84). En palabras de Lakoff y Johnson (2001), y referido a la metáfora, existen metáforas fosilizadas o muertas y metáforas vivas. Así como se dijo que la metáfora conforma redes de significado, también lo hacen los $\mathrm{x}$-femismos y esto ocurre en el estadio de semilexicalización. Además, "el grado de lexicalización de un eufemismo no es uniforme entre los hablantes de una comunidad lingüística dada. Por ello un término concreto puede ser sentido como eufemístico por

\footnotetext{
${ }^{11}$ Como puede observarse a lo largo de este trabajo, no se establece una diferencia sustancial entre el eufemismo y el disfemismo en lo que a su comportamiento pragmático hace referencia, pues los dos recursos son considerados metafóricos y ambos son intercambiables (Crespo Fernández, 2005: 98). Quizá se ha extendido mucho de lo dicho para el eufemismo al disfemismo. Para un estudio centrado en los disfemismos, Días Pérez (2012).

12 El primero de estos se da cuando la intención es eufemística a pesar de la forma. El segundo, cuando la intención es disfemística, a pesar de que se cuide la locución. Este es el caso de You aren't very Smart. Are you?, el ejemplo que presenta el autor (Crespo Fernández, 2005: 34). En este caso, se evitan términos más directos como idiota, que serían abiertamente disfemísticos, pero se tiene la intención de herir al oyente con la crítica.
} 
algunos hablantes y no por otros, especialmente entre los hablantes de las diversas variedades dialectales de una lengua y los hablantes pertenecientes a diversas generaciones" (Chamizo Domínguez, 2004: 2). Otro punto en común con la metáfora conceptual.

\section{Ejemplos de corpus}

Fernández de Molina Ortés presenta el análisis de un corpus de 64 voces recopiladas de entrevistas como variantes eufemísticas y disfemísticas para denominar algunos conceptos sobre el campo semántico del ser humano, en los siguientes ámbitos: a) órganos genitales del ser humano, b) necesidades físicas del ser humano, c) características físicas del ser humano y d) la menstruación. ${ }^{13}$

Se tomarán algunos casos de este corpus para ejemplificar cómo los eufemismos y disfemismos poseen una naturaleza metafórica. Algunas de las expresiones señaladas por la autora para denominar al 'pene' son pito y polla. Como puede observarse, la primera palabra hace referencia a la forma del órgano sexual cilíndrica y con un orificio, lo cual indica que se ha proyectado el dominio de los instrumentos sobre el de las partes del cuerpo. En el caso del término polla se personifica el órgano sexual. La proyección de dominios

\footnotetext{
${ }^{13}$ Como señala la autora (2014: 15), a las preguntas que se les hicieron sobre estos grupos temáticos el 57\% de los hablantes hizo uso de eufemismos, el $30 \%$ utilizó disfemismos y solo un 13\% habló con ortofemismos (i. e., léxico no marcado).
} 
se produce, en este caso, del dominio de los seres vivos al de las partes del cuerpo.

En cuanto a las necesidades físicas del ser humano, se hace referencia a ellas con expresiones como hacer pipí, hacer pis e ir al baño. No es difícil identificar el origen metafórico de estos términos. En los dos primeros casos, se habla del orinar como una acción del hombre, que tiene como resultado un producto el pipí o pis. En la construcción ir al baño se habla de la evacuación como la acción de dirigirse a un lugar. En todos los casos, se ubica el hecho de orinar en el ámbito más abstracto de las acciones humanas.

Similares usos metafóricos pueden constatarse en los eufemismos y disfemismos que remiten a características físicas del ser humano. Por ejemplo, ancho y grande por 'gordo' son metáforas que eluden la designación específica de la gordura, a la vez que se centran en otras características físicas, que no son mal vistas en todos los casos. Un hombre puede tener hombros anchos o medir $1.90 \mathrm{mts}$., sin ser gordo. Grandón agrega a esta significación metafórica el uso de un afijo apreciativo que actúa como modalizador y atenuador de lo dicho.

Por último, en lo que a la menstruación se refiere, algunos eufemismos con que se la nombra son regla y periodo. Estos lexemas remiten metafóricamente a la característica de cíclico del referente, que puede graficarse con la imagen de una regla. En otras palabras, se proyecta el dominio de los útiles escolares sobre el del fenómeno físico de la menstruación. No se hace referencia, por ejemplo, al hecho de que un fluido sea expelido, sino que la conceptualización del proceso focaliza su desarrollo temporal y la graficación de este. 
Otro estudio del que se pueden extraer ejemplos de conceptualizaciones metafóricas en la base de los $\mathrm{x}$-femismos es el de Crespo Fernández. El autor da cuenta de las diversas metáforas conceptuales presentes en eufemismos hallados en inscripciones funerarias de un corpus de epitafios recogidos en el cementerio de Albacete (España). Una de ellas es MORIR ES DESCANSAR, que se observó en expresiones como R.I.P (Requiescat in Pace), yacer, reposar, dormir y cementerio, que etimológicamente significa 'dormitorio' (2008: 90).

Otras expresiones metafóricas $\mathrm{x}$-femísticas son las siguientes: No te olvida(n) y iPresente! (metáfora base: MORIR ES VIVIR EN EL RECUERDO); subió al cielo y fue al cielo (MORIR ES VIAJAR, MORIR ES SUBIR); perdido por 'muerto' (LA MUERTE ES UNA PÉRDIDA); $;^{14}$ terminó su camino y finado (LA MUERTE ES UN VIAJE, LA MUERTE ES El FINAL DE ALGO).

Los disfemismos también poseen una base metafórica. La diferencia con los eufemismos reside en que la proyección metafórica que tiene como función primaria es la de mantener e intensificar la asociación entre el símbolo y el referente de modo que quede patente su lado más incómodo, en vistas a obtener algún efecto comunicativo. Uno de estos efectos puede ser el deseo de ser agresivo, que puede observarse en el uso de los términos coger, ponerla y garchar en Argentina para hacer referencia al acto sexual. En estos casos, se utiliza el ámbito de las acciones humanas de 'levan-

\footnotetext{
${ }^{14}$ La caracterización metafórica que asocia la muerte con una pérdida presenta una base metonímica, pues es a través de los efectos de la muerte que se representa la muerte.
} 
tar' y 'colocar' para referir el acto sexual. El uso de dominios más abstractos no logra aquí un efecto eufemístico.

Otros términos que pueden servir como muestras de la metaforicidad de los disfemismos son aquellos que buscan producir una ruptura con las convenciones sociales, conocidos como lenguaje políticamente incorrecto. Un caso es el uso de sudaca, que consiste en un acortamiento de la forma sudamericano y se utiliza de modo despectivo. Puede hallarse una metáfora en el hecho de que la palabra incompleta, con menor gramaticalidad, aluda a una realidad degradada.

Como ha podido observarse en los ejemplos presentados, los $\mathrm{x}$-femismos se basan en proyecciones metafóricas desde un dominio a otro que no se desea expresar con términos no marcados, i. e., ortofemismos. En el caso de los eufemismos, las proyecciones se basan en correspondencias que destacan algunos aspectos de las realidades mentadas y ocultan aquellos que pueden resultar más avergonzantes. En el caso de los disfemismos, se produce el efecto contrario: se destacan aquellas características más molestas o incomodantes de los elementos a los que se hace referencia.

\section{Conclusión}

Las metáforas están omnipresentes en el habla cotidiana, literaria, científica, etc. y - como se vio- en la estructuración de las experiencias y el obrar del hombre. Como ha podido visualizarse en este trabajo, el caso de los $\mathrm{x}$-femismos no es una excepción a esta regla. Se trata de usos metafóricos del lenguaje. El análisis de estas bases metafóricas permite co- 
nocer cómo se comprenden las diversas situaciones tabúes y las estrategias pragmáticas meliorativas y peyorativas que se aplican para hacer referencia a ellas a través del lenguaje.

\section{Bibliografía}

Aristóteles (1974 [siglo IV a.C.]), Poética, traducción de

Valentín García Yebra, Madrid, Gredos.

Busquet, J. (2007), "La utilización del lenguaje para enmas-

carar la realidad ( $¿$ Hay que cambiar las palabras para cambiar las cosas?)", Intercanvis, 19, pp. 79-85.

Días Pérez, J. (2012), Pragmalingüistica del disfemismo y la descortesía: Los actos de habla hostiles en los medios de comunicación virtual, tesis doctoral, Getafe (Madrid).

Chamizo Domínguez (2004), "La función social y cognitiva del eufemismo y del disfemismo", Panace@, V, 15. En línea: http://www.medtrad.org/pana.htm [Consulta: 03/06/2013].

Chamizo Domínguez y Sánchez (2000), Lo que nunca se aprendió en clase: eufemismos y disfemismos en el lenguaje erótico inglés, Granada, Comares.

Crespo Fernández, E. (2005), El eufemismo, el disfemismo $y$ los procesos mixtos: la manipulación del referente en el lenguaje literario inglés, tesis doctoral, Universidad de Alicante. Disponible en línea: file:///C:/Users/Soledad/ Downloads/Crespo\%20Fern\%C3\%A1ndez,\%20Eliecer.pdf [Consulta: 28-01-2015].

— (2008), "La conceptualización metafórica del eufemismo en epitafios", Estudios Filológicos, 43, pp. 83-100. 
Fernández de Molina Ortés, E. (2014), "La presencia de eufemismos y disfemismos en el campo semántico del cuerpo humano. Estudio sociolingüístico", Pragmalingüística, 22, pp. 8-30.

Gibis, R. (1992), "When Is Metaphor? The Idea of Understanding in Theories of Metaphor", Poetics Today, 13, 4, pp. 575-606.

Kirby, J. (1997), "Aristotle on Metaphor", The American Journal of Philology, IV, 118, pp. 517-554.

LAKOFF, G. (1987), Women, fire and dangerous things. What categories reveal about the mind, Chicago, University of Chicago Press

LAKoff, G. y Johnson, M. (2001 [1980]), Metáforas de la vida cotidiana, $5^{\mathrm{a}}$ ed., introducción de José Antonio Millán y Susana Narotzky, Madrid, Cátedra.

Martín DE LA RosA, M. (2002), Estudio contrastivo de la metáfora en el discurso periodístico: el conflicto de las vacas locas en la prensa española e inglesa, tesis doctoral, Madrid.

Pfaff, Gibbs y Johnson (1997), "Metaphor in using and understanding euphemism and dysphemism", Applied Psycholinguistics, 18, pp. 59-83.

Ricoeur, P. (1980 [1975]), La metáfora viva, traducción de Agustín Neira, Madrid, Ediciones Europa.

Romera, A. Manual de Retórica y recursos estilísticos. Disponible en http://retorica.librodenotas.com/Recursosestilisticos-semanticos/simil-o-comparacion [Consultado el día 10/10/12].

Vaquera Márquez, E. (1984), “La metáfora, tropo de la semejanza", Habis, 15, pp. 85-94. 
Ziemke, T. (2003), "What's that thing called embodiment?", en Alterman y Kirsh (eds.), Proceedings of the 25th Annual Conference of the Cognitive Science Society, Mahwah, NJ, Lawrence Erlbaum, pp. 1134-1139. 